\title{
Customized products and cloud service information system development research
}

\author{
Chien-Wen Hung ${ }^{\mathrm{a}}$ \\ Department of Information Management, Chia-Nan University of Pharmacy \& Science, Tainan, Taiwan
}

\begin{abstract}
This study presents a cloud service customized product information system to enable businesses to provide customized product marketing on the Internet to meet consumer demand for customized products. The cloud service of the information system development strategic framework proposed in this study contains three elements: (1) e-commerce services, (2) promotion type modules, and (3) cloud services customized promotional products. In this study, a mining cloud information system to detect customer behavior is proposed. The association rules from relational database design are utilized to mine consumer behavior to generate crossselling proposals for customer products and marketing for a retailing mall in Taiwan. The study is composed of several parts, as follows. A market segment and application of association rules in data exploration techniques (Association Rule Mining) and sequence-like exploration (Sequential Pattern Mining), efficient analysis of customers, consumer behavior, identification of candidates for promotional products, and using cloud service delivery and evaluation of targets to evaluate candidates for promotional products for production. However, in addition to cloud service customized promotional products, the quantity of promotional products sales varies for different customers. We strive to achieve increased customer loyalty and profits through the use of active cloud service customized promotional products.
\end{abstract}

\section{Introduction}

In recent years, cloud computing has always been a hot topic in the field of information. Gartner research pointed out that the world's cloud computing in 2015 the output value of 162.1 billion US dollars, compared with 1136 billion US dollars in 2014 increased by $29.9 \%$. Cloud computing is expected in 2016 the number will reach 193.2 billion US dollars. Therefore, in the information industry trends, the cloud computing is the only way to open up the market.

For enterprises, in addition to easy access to data, information technology maintenance costs, such as office software, operating systems, hardware, can be greatly reduced. Therefore, it is possible to reduce the running cost and improve the industrial competitiveness. Cloud computing represents the advent of a new business era characterized by increased productivity and flexibility in business activities. At the same time, cloud computing analytics tools to meet customer needs are a commercially competitive IT tool [16].

When the Internet environment becomes more mature, commercial activities of traditional industries experienced significant change. Many industries compete to invest in the e-commerce

\footnotetext{
${ }^{a}$ Corresponding author : cwhong@ mail.cnu.edu.tw
} 
market by making direct contact with the customer and the enterprise. E-commerce (Electronic Commerce, EC), which is a year-round Internet market without geographical borders restrictions is formed and created a substantial market opportunity. Doing business over the Internet is a new commercial activity, where customers just move the mouse to go online and shop. Given the rapid development of the technology in Internet business transactions, using the current business model, customer transaction behavior, parity, purchase, payment, and others on the Internet can be analyzed faster, more convenient, more efficient, and more economical. According to the Institute for Information Industry survey, internet sales of goods gradually increase owing to lower internet transaction prices compared with those of the physical channel. There is a lot of money-saving information that can be shared, which has resulted in the continued growth of internet trading "ecommerce" type of site visitors. The most popular "e-commerce" type websites include music, travel, shopping, computer $3 \mathrm{C}$, and fashion and beauty websites [5].

To enable customers and enterprises to feel the benefits of network marketing, one solution is to provide customized customer service and efficient means of information technology to collect, analyze, produce, and meet customer needs. Therefore, this study proposes a cloud-based customized customer service information technology to help companies to analyze quickly and accurately the customer's consumption behavior. The proposed system provides results of the analysis, which help generate active promotional products and provide customers with a lower promotional price. The system saves time for customers when buying goods partly because the individual needs are met, increasing the probability of turnover for customers and companies, which creates a win-win situation [14].

In this study, a mining Cloud computing system to detect customer behavior is proposed. The association rules from relational database design are utilized to mine consumer behavior in order to generate cross-selling proposals for a customized products design and marketing for a retailing mall in Taiwan. The other sections of the study are arranged as follows. In Section 2, we describe the Literature review and background of the case firm and summarize the goal of the research project of the case firm. Section 3 introduces the proposed Cloud Information data mining system, which contains a system framework and relational database design. Section 4 introduces the data mining process, result analysis, and customized products design. Discussions and conclusions are presented in Section 5.

\section{Literature review}

Cloud computing provides the following features [24]:

(1) Cost : Because information infrastructure is usually provided by third-party vendors, there is no need to purchase information devices for one-time or non-intensive information needs.

(2) Virtual information environment : Cloud computing environment used in the basic information technology can share the information server and storage function equipment to improve utilization.

(3) a shared information environment : that allows a large number of user groups to share resources and costs, allowing centralized information infrastructures to increase peak load times and information system utilization

(4) Scalability and flexibility : to provide cloud service resource flexibility, the user can load the peak load time engineering design content

(5) Information devices and storage location independence : support users through a Web browser from anywhere to access cloud services, regardless of their use of equipment or their access to the service network location.

Cloud computing architecture framework is shown in Figure 1.

This architectural framework focuses on providing the concepts and functions that are used in cloud computing. This cloud computing architecture is available from the perspective of IT and Information Security Professionals. The cloud architecture framework includes unique cloud features 
such as virtualization and cloud services, as well as multiple users deploying the cloud services model. [27]

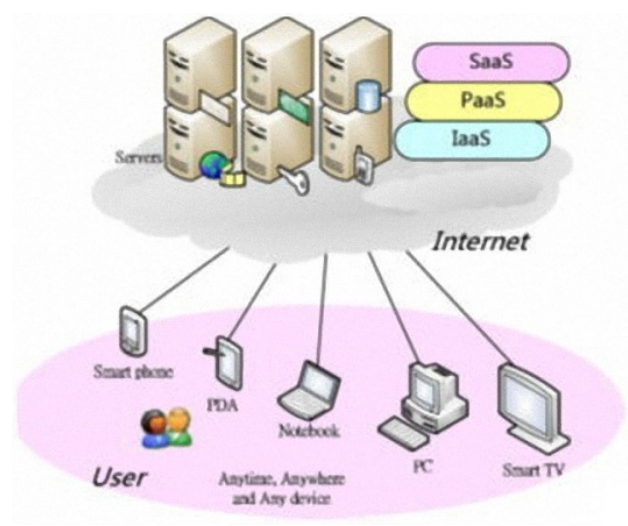

Figure 1. Cloud computing architecture framework [27].

Enterprises in cloud service environment providing customized customer service have become popular. However, quick and proper understanding of customer needs to provide customized services should be a priority of companies. Therefore, the proposed customer service for customized applications and the use of data mining techniques to collect information from a large number of promotional products to meet customer needs will result in proactive customized information to the customer to save time searching for products. The system can enhance the competitiveness of enterprises and increase corporate profits [17].

SaaS is a model that provides software through the Internet. Instead of purchasing software, users can use the Web-based software to manage their business activities without having to maintain the software. The service provider manages and maintains the software, For many small businesses, SaaS is the best way to adopt advanced technology, which eliminates the need for companies to buy, build and maintain infrastructure and applications. In recent years, the rise of SaaS has given traditional packaged software vendors real pressure.

PaaS is a platform as a service (Platform as a Service). Platform as a service is a cloud computing service that provides a computing platform and a solution stack as a service. At the typical level of cloud computing, the platform as a service layer is between software as a service and infrastructure as a service.

Platform-as-a-Service provides the ability for users to deploy and create cloud infrastructure to clients, or to use programming languages, libraries, and services. Users do not need to manage and control the cloud infrastructure, including the network, servers, operating systems or storage, but need to control the upper application deployment and application hosting environment.

PaaS takes the software development platform as a service and delivers it to the user as a softwareas-a-service (SaaS) model. Therefore, PaaS is also an application of the SaaS model. However, the emergence of PaaS can accelerate the development of SaaS, especially to accelerate the development of SaaS application speed.

Infrastructure as a Service (IaaS) is the software that consumers use to process, store, network and various basic computing resources, deploy and execute operating systems or applications, and so on. Clients can deploy and run processing, storage, networking, and other basic computing resources at will, without the need to purchase network devices such as servers and software. They cannot control or control the underlying infrastructure, but can control operating systems, storage devices, Deployed applications

This paper is to use PaaS architecture to collect customer consumption data and to analyze the interaction of purchased goods. This study aims to construct a cloud service customized product selection information system to provide a reference to the industry.

This study is composed of the following segments: 
(1) Using relevant literature examples, the collection and collation of cloud computing services for customized selection of merchandise subject to a business or organization are discussed to create an application of cloud computing services.

(2) Using relevant literature examples, the selected cloud computing services customized commodity index is collected and collated. Using questionnaire results form experts after the screening, the effect of cloud services customized commodity indexes and the construction of a cloud computing services customized selection of merchandise information system architecture are summarized using factor analysis with association rules and the neural network approach.

(3) Cloud services customized product selection system development and empirical analysis are used to strengthen the plan of the proposed cloud computing services customized merchandise selection of models and analyze the practicality of the system to provide cloud computing services model that allows corporate information.

The cloud services customized catalog is better than the traditional catalog and has two basic benefits [18]:

(1) The cloud services customized catalog offers a wide range of information and possessed more depth content. The amount of information it can provide is far more than the traditional catalog and does not have traditional catalog layout space limitations.

(2) The cloud services customized catalog has better timeliness. The content of the e-catalog can be immediate or frequently updated, providing consumers with the latest information. In contrast, the traditional catalog update takes a year or a few months below the content cycle.

\section{Methodology}

The customized products framework of the system is shown in Figure. 2,

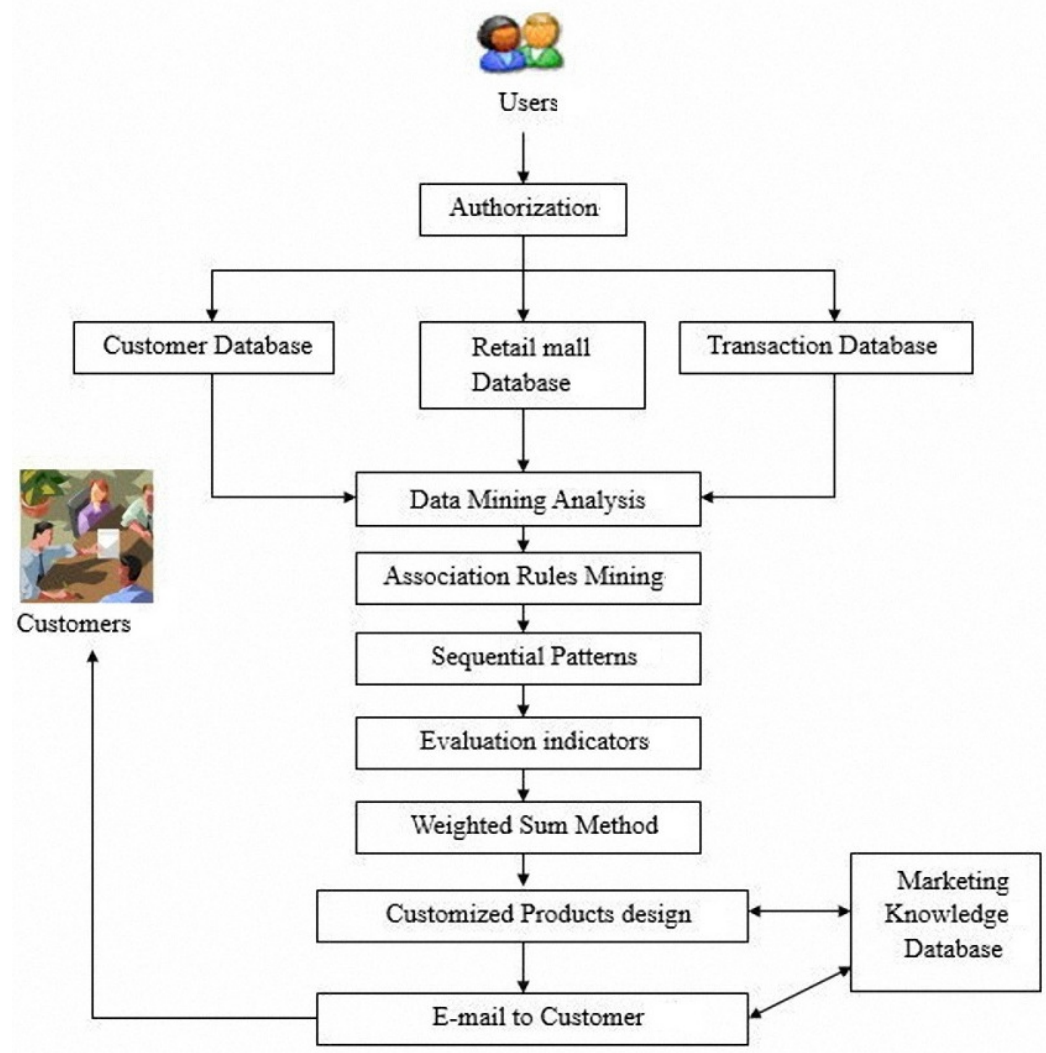

Figure 2. Customized products cloud Information System. 
The relational database management system is used to conduct the data mining which consists of four steps:

Step1: Input the system code by certification and open the databases, which consist of the customer database, the retail mall database, and the transaction database.

Step 2: Analyze the data according to the database.

Step 3: Design the customized products according to the analysis result.

Step 4: E-mail the customized products electronic catalog to the relevant branches and to the customers.

\subsection{Association rule mining}

The association rules are proposed by Agrawal and Srikant (1995). Association rule mining is widely used for analyzing the product items purchased by consumers. It is also used to support sales promotion and marketing segmentation [7-8]. The association rule is represented by $X \rightarrow Y$ where $X$ and $\mathrm{Y}$ are a set of items. This rule means that the transaction records in a business database that contain $\mathrm{X}$ tend to contain $\mathrm{Y}$. A large number of valid algorithms for mining association rules have been proposed [2-4].

In this study, a mining system to detect customer behavior is proposed. The association rules from relational database design are utilized to mine consumer behavior.

In the consumer purchase of computers and memory, for example, the association rules are as follows: Computer $\rightarrow$ Memory [support $=20 \%$, confidence $=80 \%$ ]

The formula shows that $20 \%$ of the entire transaction database will buy a computer and memory, while $80 \%$ of the total customers who purchase computers will buy them together with memory. The following steps are used to determine the association rules:

(1) First, find a collection of high-frequency items (Large Item set). This collection of support must be greater than the user customized minimum support (Minimum Support).

(2) Second, use a collection of items produced by high-frequency generating association rules.

Currently, many algorithms can identify the high-frequency items associated with a collection of rules, such as Apriori [1,18]. Apriori is the most commonly used and best-known algorithm; therefore, its data analysis will be used in this study.

\subsection{Sequential patterns}

Sequential patterns are proposed by Agrawal and Srikant (1995). The algorithm of the association rules has similar concept, mainly using items to identify the order of occurrence of the information hidden in the data. The same customer at different points in time has many transaction records, which form a sequence. Each sequence set for the project formed an ordered set (Order Set). The sequential patterns are expressed as: $\mathrm{A} \rightarrow \mathrm{B}$; where $\mathrm{A}$ and $\mathrm{B}$ are arbitrary database collection items, and $\mathrm{A} \cap \mathrm{B}$ $=\varphi$. The conditions for the establishment of sequential patterns as association rules comprise two kinds of parameter values, namely, support and confidence. Support represents some entries in the database that appear to scale. Reliability is the extent of the credibility of this sequence. Therefore, meaningful sequence patterns are greater than the degree of support and confidence threshold values set by the user.

Consumers have to buy notebooks and color laser printers, for example. The sequential pattern can be expressed as follows: Notebook $\rightarrow$ color laser printer [support $=15 \%$, confidence $=60 \%$ ]. The formula shows that $15 \%$ of the entire transaction database of customers that buy the notebook will buy a color laser printer after a period of time; the $60 \%$ denotes the customers that will buy the notebook and then buy a color laser printer.

The identification of sequential patterns with the same association rules comprises the following two steps:

(1) First, find a collection of high-frequency items. This collection of support must be greater than the user-customized minimum support. 
(2) Second, using step (1), the resulting collection of high-frequency items generated sequential patterns.

Currently, many algorithms can identify high-frequency sequential patterns collection of items, such as Apriori [1,12,29], and other algorithms. Apriori is the best known and the most commonly used algorithm.

This study will use its data analysis. The concept of association rules with similar processing steps are as follows:

(1) First, find the database to the customer number (Customer_id) primary key and the transaction time for the second sort key.

(2) Identify all projects that meet the minimum support set in the known collection of high-frequency items. This item set corresponds to a set of consecutive integers for subsequent comparison.

(3) The use of high-frequency items by Apriori algorithm collections. The minimum support to find a sequence, i.e. Large Sequence, must be met.

(4) High-frequency items from the collections are used to find the longest sequence.

\subsection{Evaluation indicators}

To assess the candidate promotional products, we propose the following three evaluation indicators: profit targets, customer satisfaction index, and turnover rate indicators. All index values must be planned after being dropped to a lesser extent.

(1) Profit targets: According to the sales of goods reached by the proportion of the target content, through the administrator to enter the appropriate average as a target value.

(2) Customer satisfaction indicators: In addition to the considerations outside business perspective, customer relationship management must also be given importance. If only corporate interests are considered, it is likely to cause bias; therefore, the customer's point of view, such as the customer satisfaction index, must also be considered. The customer can have the right not to be satisfied, which is in the target range of -1.0 to 1.0 .

(3) Turnover rate indicator: This indicator is used to assess the extent of acceptance of the promotional products. The turnover rate is defined as follows. In the range 0.0 to 1.0, Turnover rate $=$ number of promotional products accepted / Promotion Views.

\subsection{Weighted sum method}

We use multiple criteria decision analysis methods in the basic weighted sum method to calculate the final assessment score of the promotional products. Findings that show poor sorting and reporting were excluded. Suppose there are $\mathrm{m}$ candidate promotional products and $\mathrm{n}$ evaluation indicators, each candidate Promotional Products weighted total score is calculated using the following formula.

$$
A_{W S M-s c o r e}=\max _{i} \sum_{j=i}^{n} a_{i j} w_{j}, \text { for } i=1,2, \ldots, m \text {, }
$$

Where $a_{i j}$ is the $i$-th candidate promotional products, $\mathrm{j}$ is the index value of the actual indicators, and $w_{j}$ is the $j$-th index value of importance [6].

\section{Customized Products Analysis}

Profile of the case : The retail mall was established in 2000. The retail mall specializes in Daily life products. It has been a leading provider of personalized daily life products and related products for consumers. In the past decade, the firm has been proud of its products quality and the value expected by customers. The retail mall main customers are female consumers. 
From our interviews with the company marketing managers, the customized products design is the fundamental promotional tool for the firm. The customized products is designed by the marketing office based on decisions from department meetings. According to the promotion schedule, approximately three month is required for the marketing office to design and produce customized products. Furthermore, the customized products is redesigned seasonally. For example, more customized products is dedicated to facial care products and decorations products. Hence, at the beginning of the customized products would contain a hundred kinds of facial care products and 60 types of the decorations products. Upon the completion of the customized products catalog, copies of the customized products catalog are delivered to each branch five days before it is released to the public.

The customized products catalog is designed and produced by the marketing office based on aggregated information from head office, but branch office are without authority to make decisions on customized products catalog content. Hence the customized products catalog contents cannot provide a customer-oriented segmentation service for the different branch office needs. Furthermore, the cross selling customized products promotion is still neglected in current promotion policy. In addition to the traditional electronic catalog, they have another promotion mode: making advertisements for electronic magazines and electronic newspapers for the Branch Anniversary.

The data was collected from June 2015 to May 2016. The database of the system consists of three major parts, namely, customer data, product data, and transaction data.

In this study, we propose a cloud service information system prototype using data mining techniques to help enterprises find suitable promotional products for each customer in the cloud customer database. The customized products cloud service information system architecture diagram is shown in Figure 3.

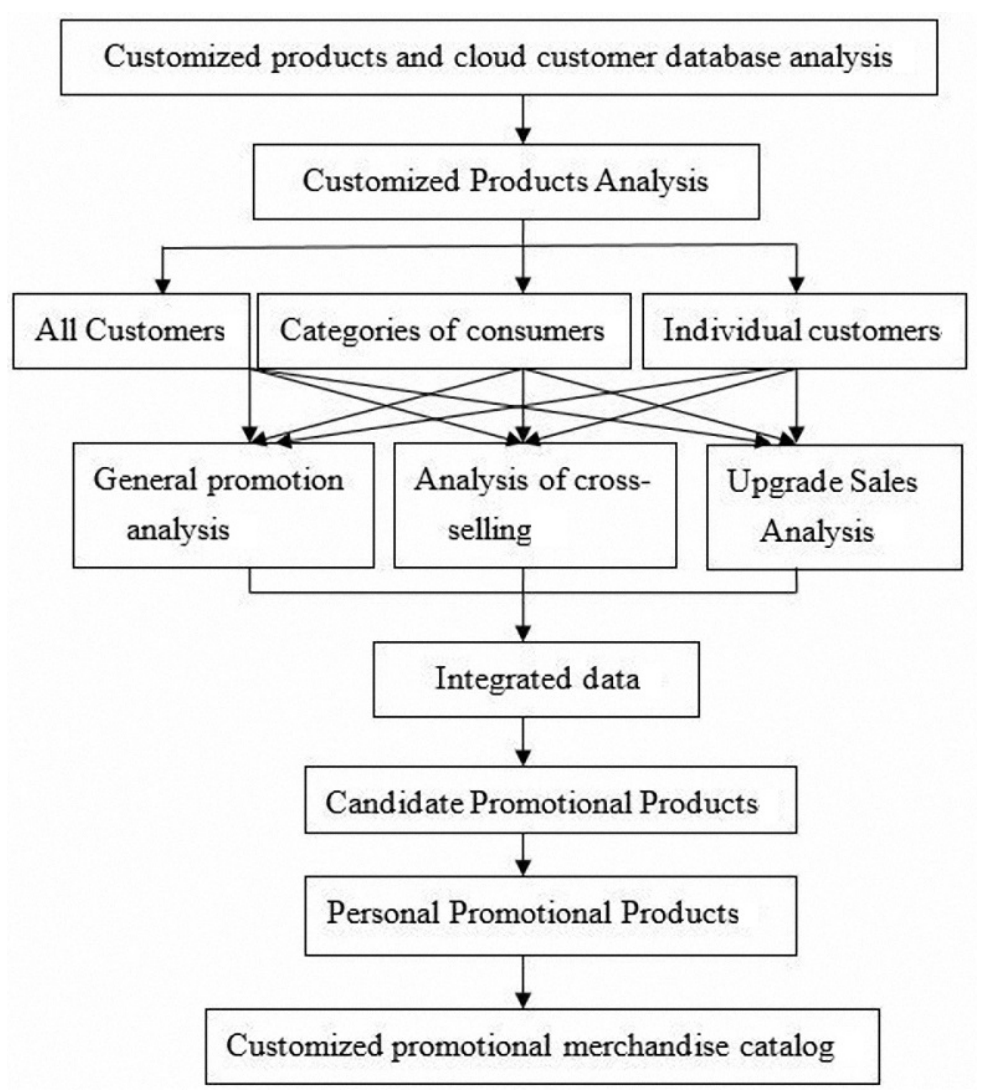

Figure 3. Customized products Cloud Service Information System Architecture Diagram. 
Each step is detailed as follows.

Step 1: Create a basic cloud customer database: This step is the main characteristic attribute in the collection of user data. It records all possible influence factors of the customer buying behavior attribute data. In this study, the cloud customer database is composed of two parts, namely, basic information and preference category. $\mathrm{C} 1$ to $\mathrm{Ci}-1$ are the basic properties of the cloud customer information, such as gender, education, salary, and others. Ci records the user's preferences for product categories, such as facial cleanser, Shampoo, and so on.

Step 2: Cloud pre-processing of customer databases and program code conversion: This step is mainly for the removal of any customer purchase records in the cloud and the retrieval of the required fields from the cloud customer database. Then, the cloud customer attribute data are matched with the users to do the coding to attribute on the clustering, which is represented as follows:

$$
\begin{gathered}
\mathrm{Ci}-1=\left\{\mathrm{A}_{1} \mathrm{~A}_{2} \ldots \mathrm{A}_{\mathrm{K}}\right\}, \mathrm{A}_{\mathrm{k}} \in\{0,1\}, 1 \leq \mathrm{k} \leq \mathrm{K} \\
\text { If } A_{h}=1 \text { then } A_{k}=1, \forall k \leq h \text { and } A_{k}=0, \forall k>h 。
\end{gathered}
$$

Step 3: Association rules: In this study, the most commonly used method of association rules is Apriori. This algorithm searches from all cloud customer transaction database to identify products that are purchased together. Meanwhile, this approach is also applied to each customer groups and individual customer transaction data to explore the various customer groups and each individual customer consumption behavior. The transaction data table is shown in Table 1.

Table 1. Transaction data table.

\begin{tabular}{|l|l|l|l|}
\hline Project ID & Product project collection & Customer ID & Category \\
\hline 1 & $\{\mathrm{P} 8, \mathrm{P} 15, \mathrm{P} 18\}$ & $\mathrm{A} 105001$ & $\mathrm{~A}$ \\
\hline 2 & $\{\mathrm{P} 2, \mathrm{P} 5, \mathrm{P} 15, \mathrm{P} 18\}$ & $\mathrm{A} 105001$ & $\mathrm{~A}$ \\
\hline 3 & $\{\mathrm{P} 3, \mathrm{P} 8, \mathrm{P} 9\}$ & $\mathrm{A} 105002$ & $\mathrm{~A}$ \\
\hline 4 & $\{\mathrm{Q} 8, \mathrm{Q} 9, \mathrm{Q} 15\}$ & $\mathrm{A} 105002$ & $\mathrm{~B}$ \\
\hline 5 & $\{\mathrm{Q} 3, \mathrm{Q} 5, \mathrm{Q} 12\}$ & $\mathrm{A} 105003$ & $\mathrm{~B}$ \\
\hline 6 & $\{\mathrm{Q} 12\}$ & $\mathrm{A} 105005$ & $\mathrm{~B}$ \\
\hline 7 & $\{\mathrm{R} 6, \mathrm{R} 18\}$ & $\mathrm{A} 105005$ & $\mathrm{C}$ \\
\hline 8 & $\{\mathrm{R} 2, \mathrm{R} 6, \mathrm{R} 10\}$ & $\mathrm{A} 105007$ & $\mathrm{C}$ \\
\hline 9 & $\{\mathrm{Q} 9, \mathrm{Q} 17\}$ & $\mathrm{A} 105007$ & $\mathrm{~B}$ \\
\hline 10 & $\{\mathrm{Q} 5, \mathrm{Q} 10, \mathrm{Q} 12, \mathrm{Q} 20\}$ & $\mathrm{A} 105008$ & $\mathrm{~B}$ \\
\hline 11 & $\{\mathrm{R} 8, \mathrm{R} 20\}$ & $\mathrm{A} 105004$ & $\mathrm{C}$ \\
\hline 12 & $\{\mathrm{R} 6, \mathrm{R} 20, \mathrm{R} 23\}$ & $\mathrm{A} 105004$ & $\mathrm{C}$ \\
\hline 13 & $\{\mathrm{R} 23\}$ & $\mathrm{A} 105004$ & $\mathrm{C}$ \\
\hline 14 & $\{\mathrm{R} 3, \mathrm{R} 6, \mathrm{R} 15\}$ & $\mathrm{A} 105006$ & $\mathrm{C}$ \\
\hline 15 & $\{\mathrm{R} 5, \mathrm{R} 17, \mathrm{R} 18, \mathrm{R} 20\}$ & $\mathrm{A} 105006$ & $\mathrm{C}$ \\
\hline
\end{tabular}

All the customer correlation patterns for the product $\{\mathrm{P} 3, \mathrm{P} 8\}$ and $\{\mathrm{P} 15, \mathrm{P} 18\}$ are obtained, including all customers who tend to purchase product P3 and product P8 P18 P15 and products purchased together. In addition, Table 2 shows that Customer ID belongs customer group A. With the association of ethnic A rule mining, we found that this population of customers often purchase products P15 and P18. Similarly, the application of association rules to individual customers (e.g. Customer ID example) identifies which customers would like to buy products P2 and P5.

Thus, in this example, a pattern of all associated products for three different types of customers (all customers, customer groups, and individual customers) is discovered and shown in Table 2. 
Table 2. Three kinds of customer type pattern-associated products.

\begin{tabular}{|l|l|}
\hline Customer Type & Pattern associated products \\
\hline All customers & $\{\mathrm{P} 3, \mathrm{P} 8\}\{\mathrm{P} 15, \mathrm{P} 18\}$ \\
\hline A customer groups & $\{\mathrm{P} 15, \mathrm{P} 18\}$ \\
\hline Individual customers (Customer 1) & $\{\mathrm{P} 15, \mathrm{P} 18\}$ \\
\hline
\end{tabular}

Step 4: Sequential patterns

Sequential patterns can be found after customers buy certain products to purchase certain other products. In this study, the use of sequential patterns from all of the customer's transaction database to identify what customers often order or purchase. Similarly, this method can also be applied to each customer groups and individual customers to explore the various customer groups and the sequence of individual customer buying patterns.

All the product pattern sequences are shown in Table 3. We acquired all of our customer's sequential pattern of the product $\{\mathrm{P} 3, \mathrm{P} 14\}$ and $\{\mathrm{P} 8, \mathrm{P} 14\}$. As stated previously, Customer A105001 belongs to customer group A. Using a sequence of ethnic pattern mining, we found that this group of customers often purchases products P5 P8.

Table 3. Three kinds of customer type sequential pattern products.

\begin{tabular}{|c|c|}
\hline Customer Type & Pattern associated products \\
\hline All customers & $\{\mathrm{P} 3, \mathrm{P} 14\}\{\mathrm{P} 8, \mathrm{P} 14\}$ \\
\hline A customer groups & $\{\mathrm{P} 8, \mathrm{P} 5\}$ \\
\hline Individual customers (Customer 1$)$ & - \\
\hline
\end{tabular}

Step 5: Evaluation Index of promotional products

All products are calculated with a weighted total score. Product promotion can be determined by fractional order. In addition, warning threshold values $(\rho)$ can also be set to remove a low fraction of products. Table 4 shows the candidate promotional products. For example, assume that the threshold value is 0.3 ; then, the sub-standard promotional products will be excluded. Finally, the price of product promotion order of $\{\mathrm{P} 16\}>\{\mathrm{P} 3, \mathrm{P} 9\}>\{\mathrm{P} 4, \mathrm{P} 8\}>\{\mathrm{P} 3, \mathrm{P} 8\}$; In addition, the product promotion sequence number is $\{\mathrm{P} 5\}>\{\mathrm{P} 9\}>\{\mathrm{P} 3\}$. In summary, when the quantity of the purchase reaches the threshold set by the policy, it becomes preferential.

Table 4. Various candidate promotional products index score and weighted total score.

\begin{tabular}{|c|c|c|c|c|}
\hline \multicolumn{2}{|c|}{$\begin{array}{l}\text { Candidate promotional } \\
\text { products }\end{array}$} & \multirow{2}{*}{$\begin{array}{l}\begin{array}{l}\text { Customer } \\
\text { satisfaction index }\end{array} \\
0.48 \\
\end{array}$} & \multirow{2}{*}{$\begin{array}{l}\text { Turnover rate } \\
\text { index }\end{array}$} & \multirow{2}{*}{$\begin{array}{l}\text { Weighted total } \\
\text { score }\end{array}$} \\
\hline \multirow{9}{*}{$\begin{array}{l}\text { Price of } \\
\text { Product }\end{array}$} & $\{\mathrm{P} 3, \mathrm{P} 8\}$ & & & \\
\hline & $\{\mathrm{P} 15, \mathrm{P} 18\}$ & 0.46 & 0.52 & 0.49 \\
\hline & $\{\mathrm{P} 4\}$ & 0.43 & 0.28 & 0.48 \\
\hline & $\{\mathrm{P} 9\}$ & 0.18 & 0.53 & 0.46 \\
\hline & $\{\mathrm{P} 4, \mathrm{P} 8\}$ & 0.52 & 0.61 & 0.54 \\
\hline & $\{\mathrm{P} 3, \mathrm{P} 9\}$ & 0.63 & 0.65 & 0.56 \\
\hline & $\{\mathrm{P} 4, \mathrm{P} 9\}$ & 0.32 & 0.46 & 0.47 \\
\hline & $\{\mathrm{P} 16\}$ & 0.83 & 0.66 & 0.69 \\
\hline & $\{\mathrm{P} 16, \mathrm{P} 18\}$ & 0.45 & 0.35 & 0.47 \\
\hline \multirow{6}{*}{$\begin{array}{l}\text { Quantity } \\
\text { of } \\
\text { Product }\end{array}$} & $\{\mathrm{P} 2\}$ & 0.36 & 0.36 & 0.46 \\
\hline & $\{\mathrm{P9}\}$ & 0.65 & 0.75 & 0.67 \\
\hline & $\{\mathrm{P} 3\}$ & 0.48 & 0.68 & 0.63 \\
\hline & $\{\mathrm{P} 5\}$ & 0.83 & 0.86 & 0.68 \\
\hline & $\{\mathrm{P} 8\}$ & 0.46 & 0.67 & 0.48 \\
\hline & $\{\mathrm{P} 10\}$ & 0.42 & 0.27 & 0.46 \\
\hline
\end{tabular}


Step 6: Customized promotional merchandise products

If all of the candidate product promotions are sent to customers, it may cause excessive opposite effect; therefore, not all candidate promotional products are sent to customers. In this system, we use the weighted sum of the three assessment methods and indicators to sort the promotional products, which can be divided into the price of products and the number of products. Figure 4,and Figure 5 shows that policymakers, according to market experience or preference, were given three kinds of indicators with different weights to calculate the sum of the weighted product candidate scores.

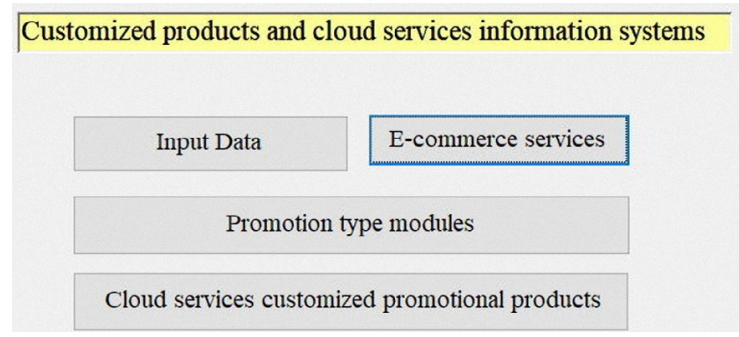

Figure 4. Customized product and Cloud services information systems

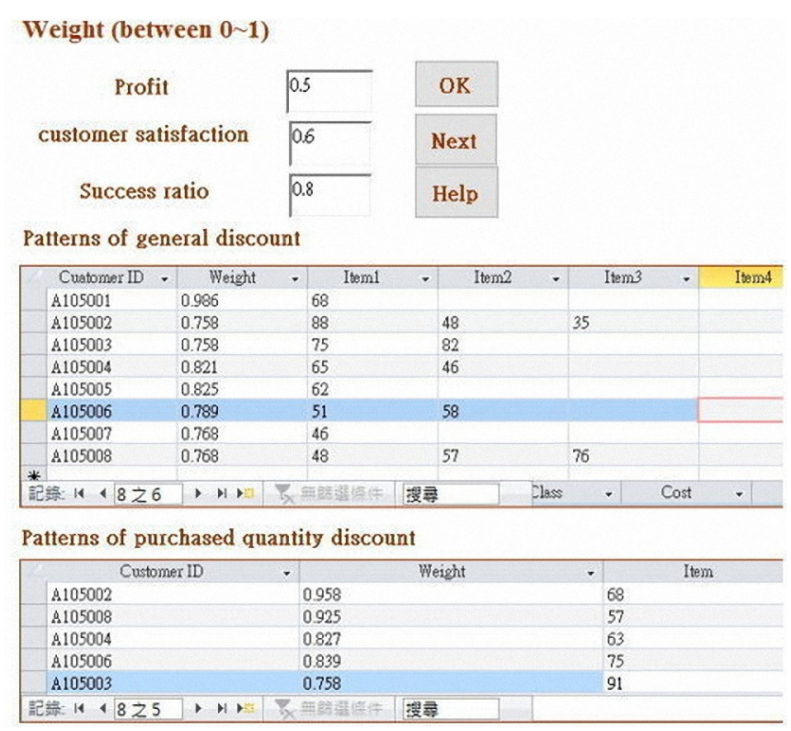

Figure 5. Customized commodity product promotions.

Therefore, when these three indicators by policy makers are found, the needs of individual customer's promotional products shall be considered in the current business situation. The main objective of the promotion is to determine the appropriate weight of each index. The system helps enterprises to efficiently deliver the customized commodity product promotion, as well as really meet the business situation and needs.

\section{Discussion and Conclusion}

The Cloud customer database developed in this research serves as the information system. After importing the benefits that can be found in a number of products imported, we found that the number is high, which is due to the adoption of a strategic customized services. Product customers must first purchase a lot or a combination. Therefore, after the import volume greatly improved, the total sales and gross profit of the product increased, as shown in Table 5, Figure 6, Figure 7, Figure 8, Figure 9.

The detailed results are shown in Figure 6, the use of cloud services information system customized products, the total sales of its products have increased. Figure 7 shows the use of cloud 
services information system customized products, the gross profit of its products have increased. Figure 8 shows the use of cloud services information system customized products, the sales improvement rate have increased. Figure 9 shows the use of cloud services information system customized products, the sales improvement increase in gross profit rate have increased.

The results of mining enabled the sales ranking of product as main promotional products and the designing of the customized products promotional catalog based on products combined. Because some customers had bought two products at the same time, in order to encourage customers to purchase a third one, which belongs to the customer product preference list.

Table 5. Cloud services information system and improvement rate of the total sales and Gross Profit.

\begin{tabular}{||l|l|l|l|l|l|l||}
\hline $\begin{array}{l}\text { Customized product } \\
\text { portfolio ratio }\end{array}$ & $\begin{array}{l}\text { P2 } \\
\text { Product }\end{array}$ & $\begin{array}{l}\text { P9 } \\
\text { Product }\end{array}$ & $\begin{array}{l}\text { P10 } \\
\text { Product }\end{array}$ & $\begin{array}{l}\text { P3 } \\
\text { Product }\end{array}$ & $\begin{array}{l}\text { P4 } \\
\text { Product }\end{array}$ \\
\hline $\begin{array}{l}\text { Before using cloud } \\
\text { services information } \\
\text { system }\end{array}$ & Total sales(quantity) & 21836 & 32652 & 38741 & 42578 & 36843 \\
\cline { 2 - 8 } & Gross Profit(Price) & 125,635 & 142,789 & 227,345 & 176,285 & 257,425 \\
\hline \multirow{2}{*}{$\begin{array}{l}\text { After using cloud } \\
\text { services information } \\
\text { system }\end{array}$} & Total sales(quantity) & 29586 & 35821 & 43258 & 48762 & 42517 \\
\cline { 2 - 8 } & Sales improvement rate & $26.19 \%$ & $8.85 \%$ & $10.44 \%$ & $12.68 \%$ & $13.35 \%$ \\
\cline { 2 - 8 } & Gross Profit(Price) & 168,523 & 182,560 & 281,405 & 237,851 & 316,580 \\
\hline
\end{tabular}

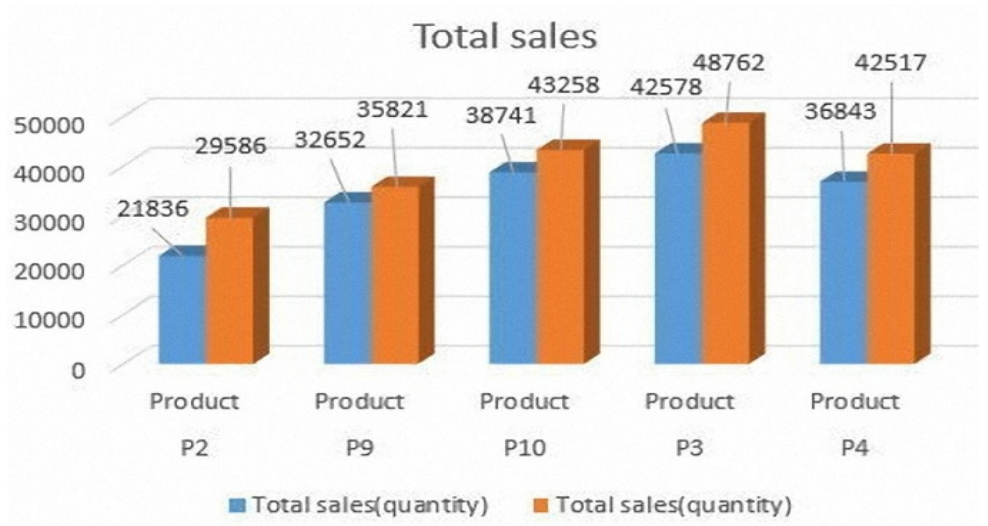

Figure 6. Comparison of total sales after the cloud services information system.

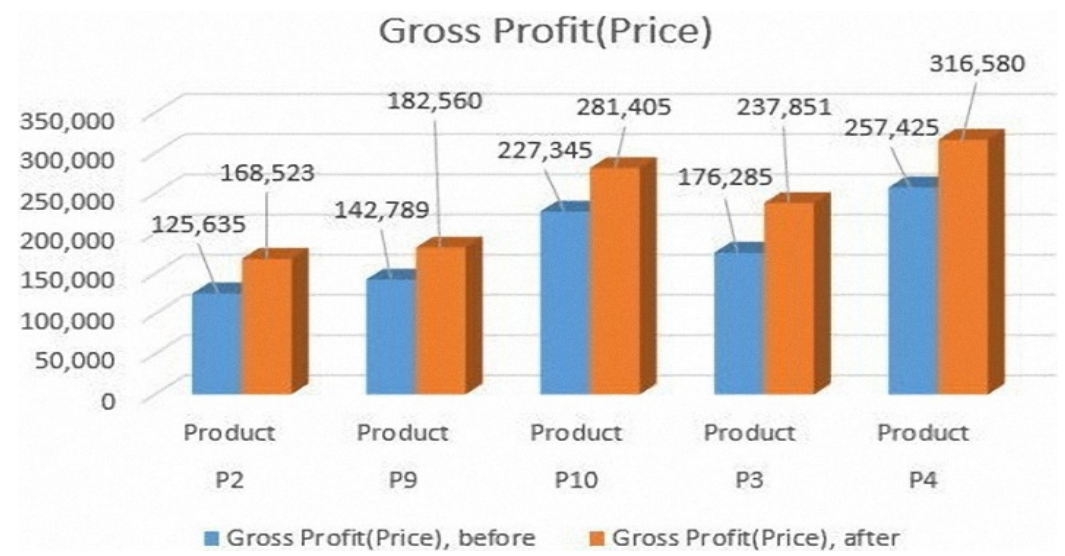

Figure 7. Comparison of Gross Profit after the cloud services information system. 


\section{Sales improvement increase rate}

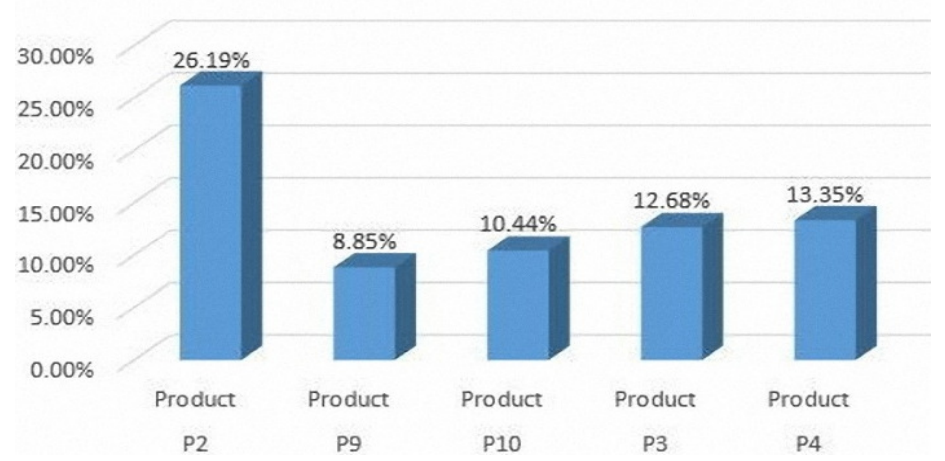

Figure 8. Comparison of sales improvement increase rate after the cloud services information system

\section{Sales Improvement increase in gross profit rate}

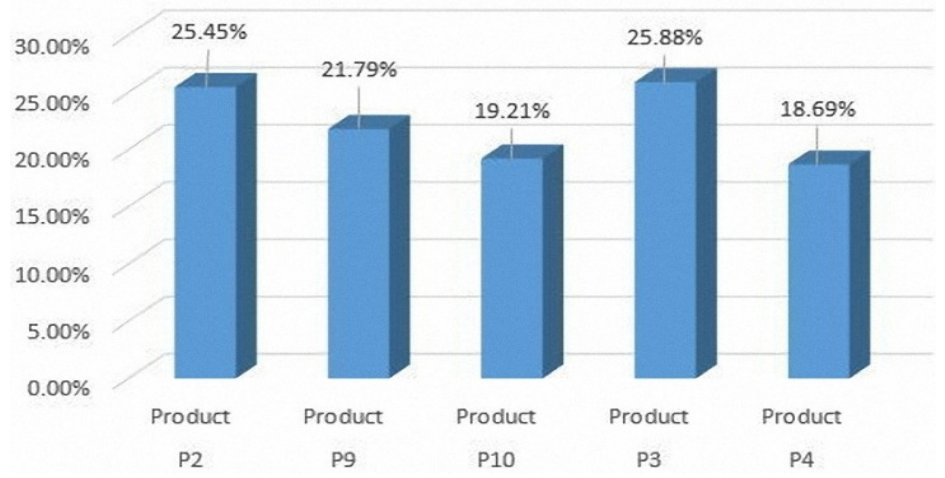

Figure 9. Comparison of sales improvement increase in gross profit rate after the cloud services information system

This research provides a cloud services information systems to enhance the sales of the case firm products by changing the original promotion method. It helps supervisors and employees make better decisions about promotional activities by providing them with useful knowledge from the new system proposed here. After applying customized products promotional catalogs in marketing, it is helpful to the company to catch on to the market acceptance of products and to know product sales conditions through the data mining system so as to mend marketing strategy and achieve the goal of product sales.

Besides, the data mining system also can correct the design of customized products catalogs according to market sales data and design customized products promotional catalogs of different periods. Thus, applying the data mining system effectively cannot only allow understanding of customers' purchasing behavior, but also provide knowledge of the cognition related to customers' purchasing for the policymaker to make the best policy.

In this paper, we developed a cloud services information system that can detect changes in customer behavior based on customer transaction data and sales products data. The advent of data mining has enhanced the accuracy of predicting customer purchase behavior. Mining for changes in customer purchase behavior is useful for satisfying customer needs in a dynamic internet business environment.

In this study, the association rules are used to identify links between customer profiles and products purchased. It provides marketing managers with a useful tool to rapidly search for valuable information based on customer transaction cloud information. Thus, it enables marketing managers to rapidly establish marketing strategies to enhance sales and profit.

For future research direction, such as sales promotion strategy and pricing strategy improvement, customers must be anticipated in different ways for cluster analysis. Considering the quick changes in 
customer preferences, companies must be able to grasp immediately the change in the customers' needs for customer retention. Therefore, dynamic data mining is essential, that is, the contents of the cloud customer database will have a transaction when the cloud service information system must correctly reflect the new database in the hidden data and reanalyze the customer's data.

Future study focus includes (1) pricing strategy and (2) dynamic data mining in both directions for further extensions and discussion to meet the business requirements. In the "pricing strategy", the competitor's pricing strategy may be taken into account. As for the "Dynamic Data Mining" in future studies, it is to allow enterprises to more securely grasp the customer by constant analysis of consumer behavior.

\section{References}

1. D.A. Aaker, Measuring brand equity across products and markets, California Management Review, 38 (3), 103-120 (1996)

2. R. Agrawal and R. Srikant, Fast algorithms for mining association rules, Proc. of the 20th International Conference on Very Large Databases, Santiago, Chile ,USA (1994)

3. R. Agrawal and R. Srikant, mining sequential pattern, Proc. of the 11th International Conference on Data Engineering, 12, 3-14 (1995)

4. S.S. Anand, A.R. Patrick, J.G. Hughes, and D.A. Bell, A data mining methodology for cross-sales, Knowledge-Based Systems, 10, 449-461 (1998)

5. A. Berson, S.J. Smith, and K. Thearling, Building Data Mining Applications for CRM, McGrawHill, USA (2015)

6. G.A. Carpenter and S. Grossberg, The ART of adaptive pattern recognition by self-organizing neural network, IEEE Computer, 21 (3), 77-88 (1988)

7. S.W. Changchien, C.F. Lee, and Y.J. Hsu, On-line personalized sales promotion in electronic commerce, Expert Systems with Applications, 27 (1), 35-52 (2004)

8. S.W. Changchien and T.C. Lu, Mining association rules procedures to support on-line recommendation by customers and products fragmentation, Expert Systems with Applications, 20 (4), 325-335 (2001)

9. Y.H. Cho, J.K. Kim, and S.H. Kim, A personalized recommender system based on web usage mining and decision tree introduction, Expert Systems with Applications, 23, 329-342 (2002)

10. R. David and V. François, Enterprise information systems state of the art: Past, present and future trends, Computers in Industry, 79, 3-13 (2016)

11. M. Gibbert, M. Leibold, and P. Gilbert, Five styles of customer knowledge management, and how smart companies use them to create value, European Management Journal, 5, 459-469, (2002)

12. J. Han, J. Pei, B. Mortazavi-Asl, Q. Chen, U. Dayal, and M.C. Hsu, Free span: frequent patternprojected sequential pattern mining, Proc. of the International Conference on Knowledge Discovery and Data Mining, Boston, MA, USA (2015)

13. D. Hoffman and T.P. Novak, A new marketing paradigm for 102 electronic commerce, The Information Society, 13, 43-54 (2010)

14. G.R, Iyer, A.D. Miyazaki, D. Grewal, and M. Giordano, Linking web-based segmentation to pricing tactics, Journal of Product \& Brand Management, 11 (5), 288-302 (2012)

15. A.N. Keller and M.R. Genesereth, Using information to create a housewares virtual Catalog, International Journal of Electronic Commerce and Business Media, 7 (4), 41-44 (2007)

16. W. Kim, Cloud computing: today and tomorrow, Journal of Object Technology, 8 (1), 65-72, (2009)

17. R.D. Lawrence, G.S. Almasi, V. Kotlyear, M.S. Viveros, and S.S. Duri, Personalization of supermarket product recommendations, Data Mining and Knowledge Discovery, 8, 11-32, (2015)

18. H. Leonard, L.R. Eduardo, and V. Stefan, A cloud brokerage approach for solving the resource management problem in multi-cloud environments, Computers \& Industrial Engineering, 95, 16$26(2016)$ 
19. C. Lin and C. Hong, Using customer knowledge in designing electronic catalog, Expert Systems with Applications, 34, 119-127 (2008)

20. D. Nash and A. Stema-Karwat, An application of DEA to measure branch cross selling efficiency, Computer Operations Research, 5, 385-392 (2013)

21. L.P. Shan and L. Jae-Nam, Using E-CRM for a unified view of the customer, CACM, 12, 95-99 (2003)

22. M.J. Shaw, C. Subramaniam, G.W. Tan, and M.E. Welge, Knowledge management and data mining for marketing, Decision Support Systems, 31, 127-137 (2011)

23. K. Stanoevska-Slabeva and B. Schmid, Internet electronic product catalogs: an approach beyond simple keyword and multimedia, Computer Networks, 32, 701-715 (2015)

24. S. Subashini and V. Kavitha, A survey on security issues in service delivery models of cloud computing, Journal of Network and Computer Applications, 34 (1), 1-11 (2011)

25. C.F. Surprenant and M.R. Solomon, Predictability and personalization in the service encounter, Journal of Marketing, 51, 86-89 (2007)

26. L. Terveen, W. Hill, B. Armento, D. McDonald, and J. Creter, PHOAKS: a system for sharing recommendations, Communications of the ACM, 40 (3), 59-62 (2015)

27. J.M. Tsai and S.W. Hung, A novel model of technology diffusion: System dynamics perspective for cloud computing, Journal of Engineering and Technology Management, 33, 47-62 (2014)

28. E. Triantaphyllou, Multi-criteria decision making methods: a comparative study, Kluwer Academic Publishers, USA (2015)

29. T.R. Xiang, J.F. Kong, L. Hao, and Q. George, Cloud-enabled real-time platform for adaptive planning and control in auction logistics center, Computers \& Industrial Engineering, 84, 79-90 (2015) 